\title{
In situ Growth of Zeolites on Metal Foamed Supports for Adsorption Heat Pumps
}

\author{
Lucio BONACCORSI ${ }^{1}$, Edoardo PROVERBIO ${ }^{1}$, \\ Angelo FRENI ${ }^{2}$ and Giovanni RESTUCCIA ${ }^{2}$ \\ ${ }^{1}$ Department of Industrial Chemistry and Materials Engineering, \\ Università di Messina, Contrada di Dio, 98166 S. Agata, \\ Messina, Italy \\ ${ }^{2} C N R$-Istituto di Tecnologie Avanzate per l'Energia \\ "Nicola Giordano", Via Salita S. Lucia sopra Contesse 5, \\ I-98126 Santa Lucia, Messina, Italy
}

Keywords: Zeolite, Coating, Metal Foams, Adsorption, Heat Pumps

In this paper, the preparation of an adsorbent bed for adsorption heat pumps obtained by depositing zeolites on metal foam structures is discussed. Zeolites, the active adsorbent phase, were directly grown by in situ synthesis on high surface area metal foams to improve heat and mass transfer in the adsorbent beds. Coatings of zeolite $4 \mathrm{~A}$ on copper foams and of zeolite $\mathrm{Y}$ on aluminum foams were prepared and characterized by SEM, XRD analysis and measurement of the water equilibrium sorption curves by thermo-gravimetric method. The results, in terms of coatings thickness and zeolite characteristics, confirmed the chance for further developments of such zeolite-metal foam composites.

\section{Introduction}

The continuous effort to improve heat and mass transfer coefficients in adsorbent beds of compressorfree heat pumps is the key issue for the development of efficient adsorption machines.

Zeolites are the common adsorbent phases used in heat-pumping/air conditioning applications since the beginning of the researches, thanks to their excellent adsorption properties (Meunier, 1998; Cacciola and Restuccia, 1999). Zeolites for adsorption purpose are commonly commercialized as powders or formed as beads or pellets. The initial use of loose zeolite grains was soon rejected due to the poor heat transfer between the adsorbent bed and the adsorber heat exchanger accordingly to the intrinsic low thermal conductivity of the zeolitic phase and the scarce contact at the zeolitemetal interface (Guilleminot et al., 1993). Further efforts to improve heat exchange led the researchers to propose, in the last 15 years, different solutions mainly based on the consolidation of the zeolite powders directly on the heat exchanger surfaces. A typical way is to mix the zeolite powder with binders and to make a covering layer directly over the metallic surface of the adsorber heat exchanger (Restuccia et al., 2001), or to

Received on May 22, 2007; accepted on August 3, 2007. Correspondence concerning this article should be addressed to L. Bonaccorsi (E-mail address: 1bonaccorsi@unime.it).

Presented at International Symposium on Innovative Materials for Processes in Energy Systems, IMPRES, Kyoto, October, 2007. pack the adsorbent powder in a graphite or metal matrix (Guilleminot et al., 1995). Such solutions have given, indeed, higher thermal conductivity but have also evidenced scarce layer porosity, so that vapour diffusion trough the zeolitic bed became the new limiting factor.

The growth of zeolite layers directly on the heat exchanger surfaces is considered by some authors (Cacciola, 1996; Tatlier et al., 1999; Tatlıer and ErdemSenatalar, 2000) the possible solution that could help to conciliate heat and mass transfer in these applications. Actually, even in this case, limitations were found. Zeolites grow quite easily on metal surfaces by hydrothermal synthesis but the layers thickness is usually limited to few tens of microns, requiring larger heat exchanger surfaces to reach the needed adsorbent mass. Therefore, the metal/zeolite mass ratio increases causing an important reduction of the heating/cooling performance.

In this paper, the direct growth of zeolites on open cell metal foams, i.e., having a permeable porosity, is proposed as innovative solution. The use of open cell metal foams in heat exchangers is already diffused in several applications where higher surface area is needed to improve heat transfer (Ashby et al., 2000). The coverage of the cellular metal with multiple depositions of the adsorbent phase can solve the abovementioned limits of the high metal/zeolite ratio in adsorption heat pumps. The tight bond between zeolite and metal substrate makes possible high heat transfer efficiency of the adsorbent bed while the cell porosity 
of the metal foam and the very thin thickness of the zeolite coating permits reaching high vapour permeability and thus good mass transfer properties.

\section{Experimental}

The growth of zeolites on open cell metal foams was obtained by in situ hydrothermal synthesis process. Two different foams have been used as substrate for two different zeolite coatings: a copper foam onpurpose prepared which was coated by layers of zeolite $4 \mathrm{~A}$ and a commercial aluminium foam coated by zeolite Y deposits.

\subsection{Zeolite 4A on copper foam}

A process to obtain the metal foam for thermal applications has been developed by the authors (Bonaccorsi et al., 2006). The foam synthesis process was based on the preparation of a precursor obtained by mixing a liquid resin, a foaming agent and a copper powder. The precursor is directly foamed and sintered on the pipe surface by a thermal treatment in a reducing atmosphere, as reported in a previous paper.

The hydrothermal synthesis was preceded by a preliminary seeding of the copper foam surface. The seeding was obtained by dip coating the foam in a solution of colloidal zeolite having molar composition: $15 \mathrm{SiO}_{2}: 1 \mathrm{Al}_{2} \mathrm{O}_{3}: 16 \mathrm{Na}_{2} \mathrm{O}: 300 \mathrm{H}_{2} \mathrm{O}$, prepared the day before and left ageing $24 \mathrm{~h}$ at room temperature. The wet seeded foam was then exposed to the hydrothermal synthesis in a reactor flask filled by the reacting solution. The molar composition of the synthesis solution used for the zeolite $4 \mathrm{~A}$ growth was: $1.9 \mathrm{SiO}_{2}: 1 \mathrm{Al}_{2} \mathrm{O}_{3}: 3.3 \mathrm{Na}_{2} \mathrm{O}: 147 \mathrm{H}_{2} \mathrm{O}$, and was prepared starting from a sodium aluminate solution, made by dissolving hydrate alumina powder $\left(\mathrm{Al}_{2} \mathrm{O}_{3} 65 \%\right.$ Riedelde-Haen) in a caustic solution, to which a sodium silicate solution (27.5\% $\mathrm{SiO}_{2}-8 \% \mathrm{Na}_{2} \mathrm{O}$ BHD) was added. The reacting mixture was heated up to $368 \mathrm{~K}$ for about $10 \mathrm{~h}$ to induce zeolite crystals formation and growth. The coated foam was then washed with distilled water several times and dried at $353 \mathrm{~K}$ overnight.

To increase the quantity of zeolite deposited in the foam, the hydrothermal synthesis was repeated again maintaining the same reaction parameters.

\subsection{Zeolite $Y$ on aluminum foam}

The foam used for coating was a commercial open cell aluminium foam having the following properties: bulk density $=0.2 \mathrm{~g} / \mathrm{cm}^{3}$, porosity $=93 \%$ and $16 / \mathrm{cm}$ pores. As in the zeolite 4A deposition, a colloidal seed solution was used for the synthesis solution. Differently from the previous case, the metal foam was directly exposed to the synthesis solution without preliminary seeding. The synthesis mixture used to deposit zeolite $\mathrm{Y}$ was obtained starting from the same raw materials used for zeolite 4A synthesis. A quantity of $5 \%$ of seed solution was added to the synthesis solution and the mixture was left ageing for $24 \mathrm{~h}$ at room temperature in a reactor flask. Finally, the aluminium foam was plunged into the reactor flask and the temperature increased to $368 \mathrm{~K}$ for about $4 \mathrm{~h}$. The coated foam was then washed with distilled water several times and dried overnight.

A second hydrothermal synthesis was performed on coated samples to increase the zeolite layer thickness following conditions and formulation of the first deposition.

\subsection{Zeolitic phase evaluation}

The coating morphology and the foam surfacecovering grade were evaluated by means of scanning electron microscope observation $(5600 \mathrm{LV}$ operated at $20 \mathrm{kV}$, JEOL). The identification of the coating zeolite phases was performed for foam samples by X-ray diffraction analysis using an ITALSTRUCTURE APD 2000 diffractometer with $\mathrm{CuK} \alpha$ radiation $(30 \mathrm{kV}$ and $40 \mathrm{~mA}$ ). Before the analysis, the foam samples were manually grinded and the excess metal particles were removed.

\subsection{Water adsorption properties evaluation}

The sorption properties of the synthesised zeolites were evaluated by measuring the water adsorption equilibrium by a thermogravimetric technique based on the use of a Cahn 2000 microbalance. A typical measurement was as follows: about $50 \mathrm{mg}$ of coated foam was loaded in the vacuum-tight vessel of the balance and then degassed under vacuum for $24 \mathrm{~h}$. Afterwards, a constant water vapour pressure was imposed over the sample by connecting the vessel with a thermostated evaporator. Once fixed the isobaric conditions, a number of equilibrium points were taken by directly measuring the sample weight variation corresponding to stepwise temperature changes.

\section{Results and Discussion}

\subsection{Zeolite 4A growth on copper foam}

The copper foams on purpose prepared belong to the category of the open-cell structures because of the interconnected porosity which is permeable to gas and liquids. The final foam density, measured after the metal particles sintering, was $\sim 0.5 \mathrm{~g} / \mathrm{cm}^{3}$ while the porosity could be varied between 75 and $80 \%$ in reason of the quantity of foaming agent used. Microphotographs of the copper foam obtained by SEM analysis showed a highly irregular open-porous structure with large surface area and a bimodal pore size distribution made of larger pores, sizing from 100 to $500 \mu \mathrm{m}$, and smaller pores in the $0.1-10 \mu \mathrm{m}$ size range. $\mathrm{X}$-ray diffraction analysis confirmed the growth of zeolite 4A crystals tightly bonded to the metal substrate thanks to a metal oxide interlayer formed at the foam surface in the synthesis environment (Figures $\mathbf{1}$ and 2).

The morphology of the zeolite 4A layers obtained after the two deposition treatments is the result of 


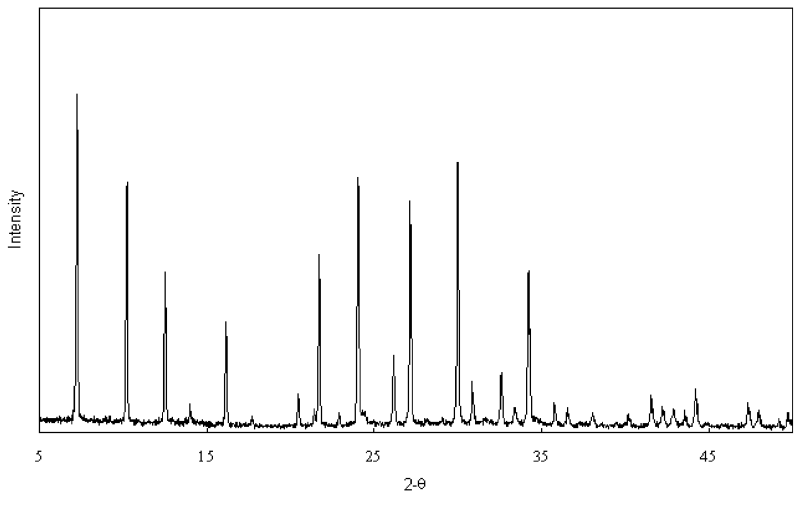

Fig. 1 X-ray diffraction pattern of the zeolite 4A coating

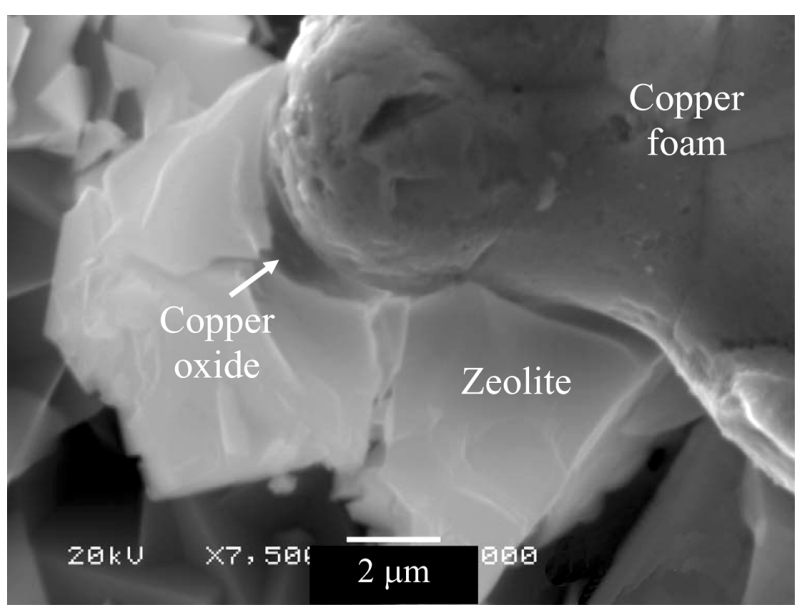

Fig. 2 Zeolite $4 \mathrm{~A}$ crystals and the metal oxide interlayer

several competing growing mechanisms that occurred in the reacting solution. The zeolite crystals formation in the first synthesis was driven by the preliminary foam surface seeding that is a well known methodology to induce the crystallization (Cundy and Cox, 2005) and, as in this case, to improve the coating accretion (Clet et al., 1999).

After the first deposition, the zeolite accretion was mainly due to a secondary growth of the pre-formed layers, consisting of aggregates of intergrown crystals densely packed covering the whole foam surface, as shown in Figure 3. The original foam porosity was maintained even after the second deposition, ensuring the needed interconnectivity for efficient vapour diffusion and then high mass transfer coefficients. The final coating was estimated to be $10 \mu \mathrm{m}$ in thickness for a total $17 \%$ by weight of zeolite $4 \mathrm{~A}$ grown on the copper foam surface.

\subsection{Zeolite $Y$ growth on aluminium foam}

The growth of zeolites on aluminium supports is generally quite difficult due to the solubility of aluminium metal in the hydrothermal synthesis environment. Recently Munoz et al. (2005) have grown zeo-

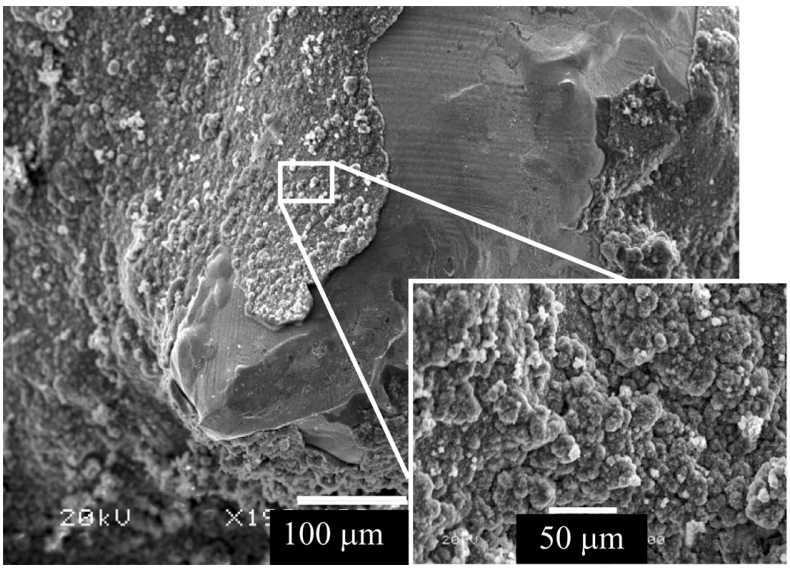

Fig. 3 SEM image of the copper foam after the two depositions

lite $\mathrm{Y}$ on aluminium alloy ( $\mathrm{Al} 2024-\mathrm{T} 3$ ) sheets by a three-step method, growing firstly a layer of zeolite ZSM-5 to make a protection for the aluminium to the corrosion attack caused by the high $\mathrm{pH}$ conditions required for zeolite $\mathrm{Y}$ synthesis. According to the method developed in this work, the surface reactivity that the aluminium foam showed during the zeolite synthesis was used to induce crystals nucleation and growth directly at the metal surface. The metal foam, indeed, was not treated by seeding to prevent corrosion in the colloidal seed solution but seeds were added to the reacting solution after raw materials as last component to induce the zeolite $\mathrm{Y}$ nucleation, according to the formulation reported in Robson (2001).

In the adsorption heat pumps, zeolite $\mathrm{Y}$ permits to use a wider range of vapours and lower desorption temperatures compared to zeolite 4A. Furthermore, aluminium is the metal showing the best thermal properties per unit mass. Such advantages validate the efforts made to growth zeolite $\mathrm{Y}$ on aluminium foams.

After the first deposition treatment, the foam surface appeared quite corroded but covered with a significant formation of zeolite $\mathrm{Y}$ crystals grown over a layer of aluminium oxide (Figure 4), as confirmed by the X-ray diffraction pattern made on the grinded foam powder (Figure 5).

The second synthesis process increased the zeolitic coating thickness without a further corrosive attack of the aluminium core, already protected by the previous deposition, so that the original open cell structure was maintained and the coated foam showed still the mechanical resistance needed for heat pump applications.

The zeolite morphology, as for the copper foam, is evidently consequent to a secondary growth mechanism where the crystals aggregated in packed and compacted structures. The total amount of zeolite Y deposited on the aluminium foam at the end of the two synthesis processes was about $15 \%$ by weight. 


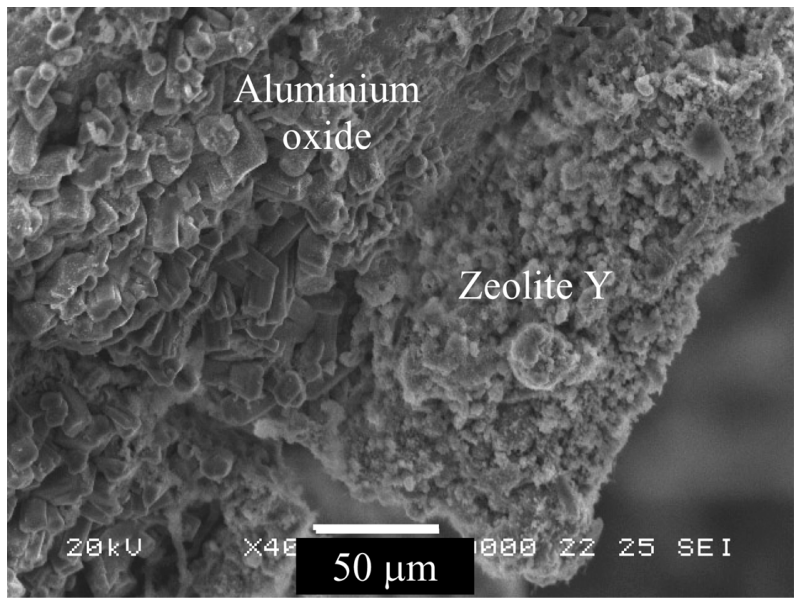

Fig. 4 SEM image of the zeolite Y coating over the aluminium foam

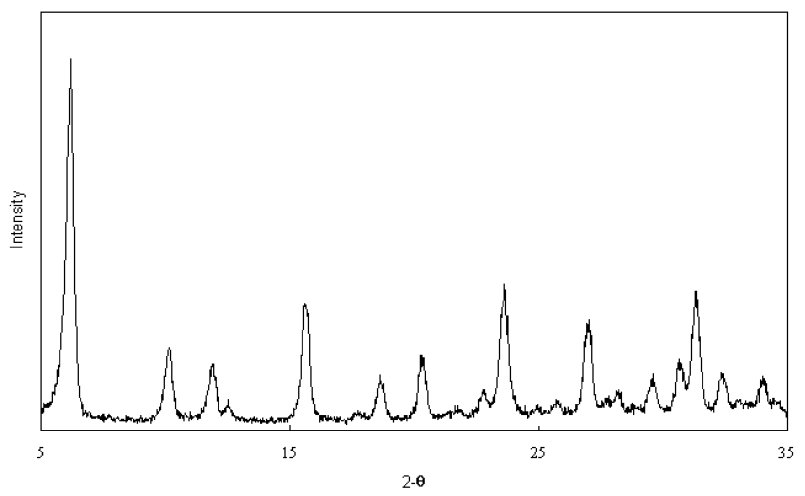

Fig. 5 X-ray diffraction pattern of the zeolite Y coating

\subsection{Water sorption properties}

Figure 6 shows the isobar curves measured in the pressure and temperature range of 10-60 mbar and 20$220^{\circ} \mathrm{C}$, for zeolite $4 \mathrm{~A}$ coating on the copper foam and for zeolite $\mathrm{Y}$ on aluminium foam (Figures 6(a) and 6(b) respectively).

It was found that the isobars measured for the zeolite 4A perfectly match with the typical isobars for a commercial zeolite 4A (Breck, 1974; Gorbach et al., 2004). Indeed, the zeolite regularly increases its water uptake when the temperature decreases or the pressure increases. The zeolite coating deposited requires a regeneration temperature of $200-220^{\circ} \mathrm{C}$, besides, no hysteresis was found.

Similar conclusions can be drawn for the zeolite Y coating, even if a slight reduction (2-3\% by weight) of the maximum adsorption capacity with respect to typical values for commercial zeolites Y-type is observed. Such lower performance is probably due to the difficulty to estimate the real weight of the zeolite coating from the underneath substrate of aluminium oxide covering the metal surface. It is worthy to mention that

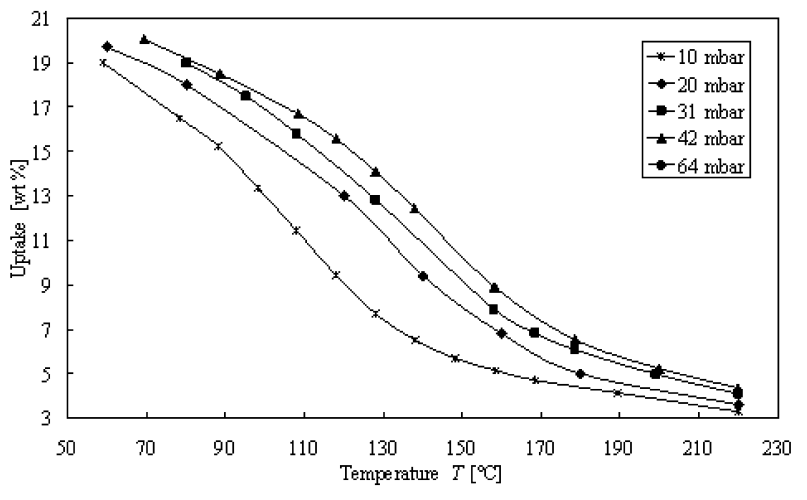

(a)

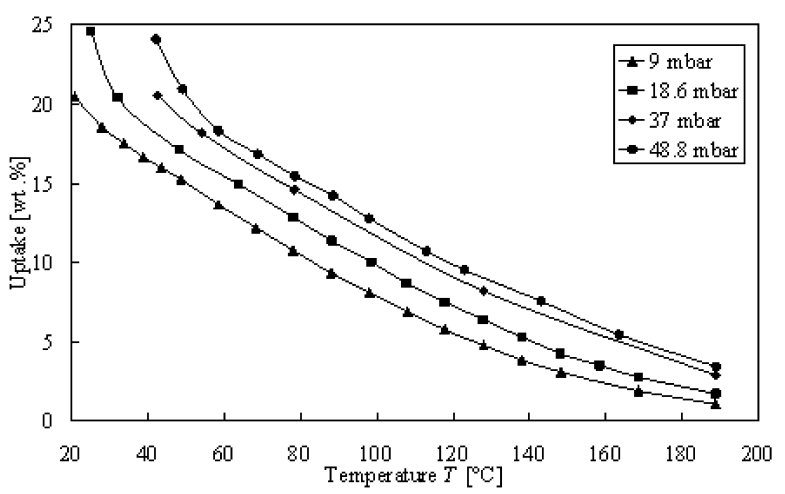

(b)

Fig. 6 Coating-water sorption isobars. Zeolite 4A on copper foam (a), zeolite $\mathrm{Y}$ on aluminium foam (b)

the synthesised zeolite Y coating shows a lower regeneration temperature, as most of the adsorbed water can be rejected at $180-200^{\circ} \mathrm{C}$. This effect is due to the weaker interaction between the adsorption sites and the water molecules, which can be more easily desorbed from the sodalite cage of the zeolite Y framework.

The experimental data were used in order to plot the isosteric charts presented in Figure 7. The typical cooling $\left(T_{\mathrm{ev}}=10^{\circ} \mathrm{C}, T_{\text {ads }}=T_{\text {con }}=35^{\circ} \mathrm{C}, T_{\text {des }}=200^{\circ} \mathrm{C}\right)$ and heating $\left(T_{\mathrm{ev}}=12^{\circ} \mathrm{C}, T_{\text {ads }}=T_{\text {con }}=60^{\circ} \mathrm{C}, T_{\text {des }}=200^{\circ} \mathrm{C}\right)$ cycles depicted in Figure 7 demonstrate that the synthesised zeolite 4A can be efficiently used as adsorbent material for adsorption chillers/heat pumps driven by high temperature heat sources. Indeed, the variation of uptake per cycle is $14 \mathrm{wt} \%$ and $9 \mathrm{wt} \%$ for cooling and heat pumping, respectively. The corresponding performance calculated by means of an already developed thermodynamic model (Cacciola and Restuccia, 1995) are: cooling coefficient of performance (COP) is 0.45 , heating COP is 1.39 (single bed configuration). Similar values of cooling and heating COP are obtained for the Y-type zeolite and the cycle plotted in Figure 8. In this case, a mid-level heat source (desorption temperature of $150^{\circ} \mathrm{C}$ ) is required for cooling, while higher desorption temperature (about $180^{\circ} \mathrm{C}$ ) is necessary for efficient heat pumping. 


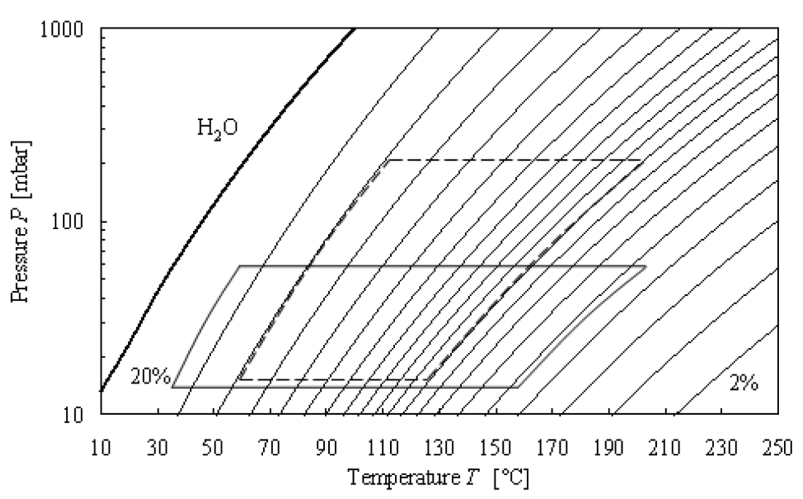

Fig. 7 Zeolite $4 \mathrm{~A}$ on copper foam: typical cooling $\left(T_{\mathrm{ev}}=\right.$ $10^{\circ} \mathrm{C}, T_{\text {ads }}=T_{\text {con }}=35^{\circ} \mathrm{C}, T_{\text {des }}=200^{\circ} \mathrm{C}$ ) and heat pumping $\left(T_{\mathrm{ev}}=12^{\circ} \mathrm{C}, T_{\mathrm{ads}}=T_{\text {con }}=60^{\circ} \mathrm{C}, T_{\mathrm{des}}=\right.$ $200^{\circ} \mathrm{C}$ ) cycle plotted over the adsorption isosters

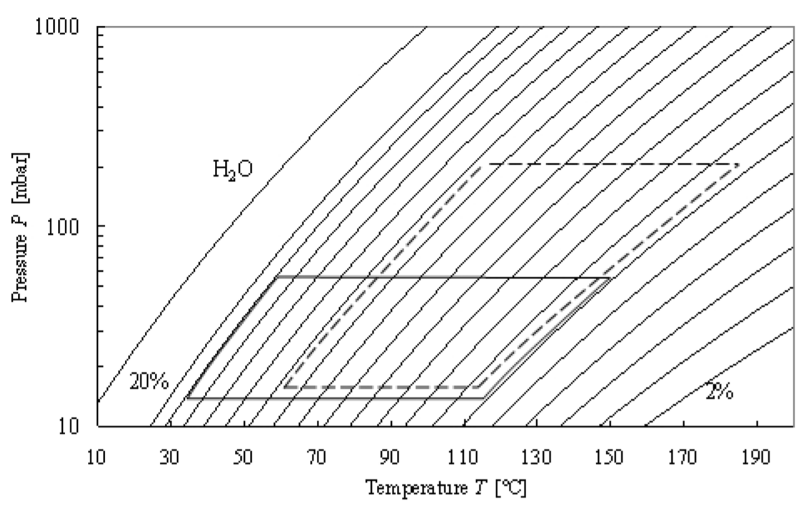

Fig. 8 Zeolite $\mathrm{Y}$ on aluminum foam: typical cooling $\left(T_{\mathrm{ev}}=\right.$ $10^{\circ} \mathrm{C}, T_{\text {ads }}=T_{\text {con }}=35^{\circ} \mathrm{C}, T_{\text {des }}=150^{\circ} \mathrm{C}$ ) and heat pumping $\left(T_{\mathrm{ev}}=12^{\circ} \mathrm{C}, T_{\mathrm{ads}}=T_{\text {con }}=60^{\circ} \mathrm{C}, T_{\text {des }}=\right.$ $180^{\circ} \mathrm{C}$ ) cycle plotted over the adsorption isosters

According to Meunier (1998), the growth of zeolite layers on the metal tubes of the adsorber demonstrated very high heat rates, higher than any other proposed solution. Nevertheless, the conclusive demonstration of the effective improvement of heat and mass transfers due to the zeolite coating on metal foams is to measure the bed dynamic properties. A prototype adsorption heat pump based on this technology will help to such evaluation and this will be the object of a next work.

\section{Conclusions}

A heat exchanger design based on the use of opencell metal foams, thanks to the favourable high surface area and higher zeolite/metal mass ratio, could represent a valid alternative to maintain the sorption thermodynamic cycle efficiency while increasing the exchange surface area. To this aim, copper and aluminium foams were respectively coated by zeolite $4 \mathrm{~A}$ and zeolite Y layers obtained by an in situ synthesis methodology in order to improve heat and mass transfers for heat pump applications.

The zeolite 4A coating was obtained on expressly prepared copper foam, while for the zeolite Y deposition a commercial-one was used. In both of the cases, the zeolitic layers demonstrated good bond properties with the metal substrate and up to $15-17 \%$ (by weight) of zeolite was deposited by a double synthesis process.

The water adsorption capacity of the zeolite/foam composites in the range of temperature and water pressure tested is comparable with that of commercial zeolites. Such results can be considered as an encouraging starting point for a further development of a prototype adsorption heat pump based on zeolite-coated metal foam adsorbers.

\section{Literature Cited}

Ashby, M. F., A. Evans, N. A. Fleck, L. J. Gibson, J. W. Hutchinson and H. N. G. Wadley; Metal Foams a Design Guide, Butterworth-Heinemann, Burlington, U.S.A. (2000)

Bonaccorsi, L., A. Freni, E. Proverbio, G. Restuccia and F. Russo; "Zeolite Coated Copper Foams for Heat Pumping Applications," Microporous Mesoporous Mater., 91, 7-14 (2006)

Breck, D. W.; Zeolites Molecular Sieves, John Wiley \& Sons, New York, U.S.A. (1974)

Cacciola, G.; "Innovative Adsorbent Materials to be Used in Heat Pump Systems," Proc. 9th IUPAC CHEMRAWN, pp. 131-137, Seoul, Korea (1996)

Cacciola, G. and G. Restuccia; "Reversible Adsorption Heat Pump: a Thermodynamic Model," Int. J. Refrig., 18, 100-106 (1995)

Cacciola, G. and G. Restuccia; "Adsorption and Its Applications in Industry and Environmental Protection," Stud. Surf. Sci. Catal., 120B, 949-978 (1999)

Clet, G., J. C. Jansen and H. van Bekkum; "Synthesis of a Zeolite Y Coating on Stainless Steel Support," Chem. Mater., 11, 16961702 (1999)

Cundy, C. S. and P. A. Cox; "The Hydrothermal Synthesis of Zeolites: Precursors, Intermediates and Reaction Mechanism," Microporous Mesoporous Mater., 82, 1-78 (2005)

Gorbach, A., M. Stegmaier and G. Eigenberger; "Measurement and Modelling of Water Vapour Adsorption on Zeolite 4A-Equilibria and Kinetics," Adsorption, 10, 29-46 (2004)

Guilleminot, J. J., A. Choiser, J. B. Chalfen, S. Nicolas and J. L. Reymoney; "Heat Transfer Intensification in Fixed Bed Adsorbers," Heat Recovery Systems \& CHP, 13, 297-300 (1993)

Guilleminot, J. J., J. B. Chalfen and F. Poyelle; "Mass and Heat Transfer in Adsorbent Consolidate Composites. Influence on Performances of an Adsorption Heat Pump," Proc. 19th Int. Congress of Refrigeration, vol. IVa, pp. 261-266, The Hague, the Netherlands (1995)

Meunier, F.; "Solid Sorption Heat Powered Cycles for Cooling and Heat Pumping Applications," Appl. Therm. Eng., 18, 715-729 (1998)

Munoz, R., D. Beving, Y. Mao and Y. Yan; "Zeolite Y Coatings on Al-2024-T3 Substrate by a Three-Step Synthesis Method," Microporous Mesoporous Mater., 86, 243-248 (2005)

Restuccia, G., A. Freni, A. Vita and G. Cacciola; "Zeolite Compact Layers Bound to Metal Support for Thermally Efficient Adsorption Refrigeration Systems," Mat. Eng., 12, 315-328 (2001)

Robson, H.; Verified Synthesis of Zeolitic Materials, 2nd ed., pp. 156-158, Elsevier Science B.V., Amsterdam, the Netherlands (2001) 
Tatlier, M., B. Tantekin-Ersolmaz and A. Erdem-Senatalar; "A Novel Approach to Enhance Heat and Mass Transfer in Adsorption Heat Pumps Using the Zeolite-Water Pair," Microporous Mesoporous Mater., 27, 1-10 (1999)
Tatlier, M. and A. Erdem-Senatalar; "Optimization of the Cycle Durations of Adsorption Heat Pumps Employing Zeolite Coatings Synthesised on Metal Supports," Microporous Mesoporous Mater., 34, 23-30 (2000) 